\title{
Comparison of aircraft engine performance and emission analysis using alternative fuels
}

\author{
Muhammad Hanafi Azami*, Mark Savill and \\ Yi-Guang Li
}

Cranfield University,

Centre for Propulsion Engineering,

Whittle Building B52, School of Aerospace,

Transport and Manufacturing,

Cranfield, Bedfordshire MK43 0AL, UK

Email:m.azami@cranfield.ac.uk

Email: mark.savill@cranfield.ac.uk

Email: i.y.li@cranfield.ac.uk

*Corresponding author

\begin{abstract}
Following the successful flights of many commercial aircraft running with alternative fuels, the present study focuses on aircraft engine performance and emission analysis. The analysis of aircraft engine performance (thrust, fuel flow and specific fuel consumption) for different blended mixing ratio percentages of biofuels (Camelina and Jatropha) with Jet-A, at different flight conditions using in-house computer software codes, PYTHIA and TURBOMATCH. Emission analysis utilised HEPHAESTUS in-house software to predict nitrous oxides and carbon monoxide emission at various flight conditions. A model three-shaft high-bypass-ratio engine, similar to the RB211-524, was used. Blended fuels exhibited a slight improvement in engine performance at higher mixing ratio percentages; with Jatropha biofuel surpassing Camelina biofuel in terms of all considered performance indexes. Nitrous oxides can be reduced using pure Jatropha biofuel as compared to kerosene fuel for every flight condition. However, for carbon monoxide emission strongly depends on the combustor inlet conditions and flight phases.
\end{abstract}

Keywords: Camelina biofuel; emissions; engine performances; Jatropha biofuel.

Reference to this paper should be made as follows: Azami, M.H., Savill, M. and Li, Y-G. (2017) 'Comparison of aircraft engine performance and emission analysis using alternative fuels', Int. J. Sustainable Aviation, Vol. 3, No. 1, pp.43-63.

Bibliographical notes: Muhammad Hanafi Azami is a PhD Researcher in Centre for Propulsion, School of Aerospace, Transport and Manufacturing, Cranfield University. He awarded MSc (Mechanical Engineering-Aerospace) and BEng (Aerospace Engineering) in International Islamic University Malaysia. His research focus area in aerospace propulsion technologies includes pressure gained combustor, performance and emissions of aero-gas turbines, alternative fuels, hybrid rocket technology and optimisation. $\mathrm{He}$ granted Malaysian Government scholarship for higher education studies. He is a graduate member of Board of Engineer Malaysia (BEM), member of Institution of Engineering and Technology (IET) and hold Student-toProfessional membership of American Institute of Aeronautics and Astronautics (AIAA). Previously, he worked as part-time lecturer in various 
public and private universities in Malaysia. He has published in reputable journals and presented technical papers in AIAA conferences.

Mark Savill FHEA, FRAeS, C.Eng is a Professor of Computational Aerodynamic Design and Head of the Power \& Propulsion Sciences Group at Cranfield University. He collaborates closely with others across the university, particularly on design optimisation and multidimensional analysis techniques applied to whole aircraft configurations as well as alternative energy windturbine, marine tidal turbine and micro-combustor power generators. $\mathrm{He}$ also focuses on gas turbine environmental emission studies, notably with CLEANSKY and other support, and more general complexity science analyses for distributed electrical power supply via smart grids, as a contributor to the wider Cranfield Complex Systems Research Centre. He works closely with Airbus and in cooperation with a wide range of academics, including former colleagues at Cambridge University (where he is a Life Fellow of Girton College) as well as with other UK and international collaborators, on topics of propulsion integration, performance, noise pollution and mixing processes. His academic standing is widely regarded as first class throughout UK and world.

Yi-Guang $\mathrm{Li}$ is a Senior Lecturer in Center for Propulsion Engineering, Cranfield University in Gas Turbine Performance and Diagnostics. His areas of expertise include engine, powertrains and alternative fuels, gas turbine and propulsion, gas path diagnostics and prognostics, gas turbine life and power systems and turbines. He has PhD from Cranfield University (2001), MSc from Northwestern Polytechnical University, China (1989) and BSc from Nanjing University of Aeronautics and Astronautics (1984). Currently he is a member of American Society of Mechanical Engineers (ASME), a fellow of Higher Education Academy (HEA) of UK, and a member of Combined Heat and Power Association (CHPA). He is a Director of civil aircraft engine designtraining program sponsored by Aviation Industry Corporation of China (AVIC). He has research collaborations with different industrial partners including Manx Electricity Authority (MEA), Isle of Man, UK and Aero Engine Corporation of China (AECC).

This paper is a revised and expanded version of a paper entitled 'Comparison of Aircraft Engine Performance Using Alternative Fuels', presented in International Symposium on Sustainable Aviation (ISSA 2016), Istanbul, Turkey.

\section{Introduction}

In the modern era, airplanes are the preferred mode of transportation especially for long distance since it is safer and much more frequent. The demands have urged the airline industries to grow expansively. However, this growth embraces myriad problems, economically and environmentally. There are two main concerns that need to be addressed: energy crisis and environmental crisis. For instance, oil demand will hike and the fuel price reaches a peak, while the pollutant generations emitted into the atmosphere are not easily controllable which results in greenhouse gas (GHG) effects. 
The world would need 50\% more energy in 2030 than today as reported by the International Energy Agency (IEA) (Ashraful et al., 2014). More than 90\% of energy consumption from the transportation sector comes from fossil fuels and a small amount from natural gas and renewable energy sources (Atabani et al., 2012; Maity et al., 2014). The scarcity of the conventional oil and natural gas reserves will diminish after approximately 41.8 and 60.3 years, respectively (Ashraful et al., 2014). With this rapid increase in transportation fuel demand trends, environmental concerns and depletion of fossil fuels have become increasingly important to adopt policies to minimise the impact of global warming (Brennan and Owende, 2010) and also forces scientists and researchers to develop alternative fuels that can approximate the properties and performance of petroleum-based fuel (Tüccar and Aydın, 2013) to alternative biofuels. Therefore, alternative sources and renewable energy are becoming more feasible and urgently needed.

The Kyoto Protocol of 1997 pointed out a 5.2\% reduction in GHG emissions worldwide from the values reported in the year 1990. Aircraft gas turbine exhaust is composed of carbon monoxide $(\mathrm{CO})$, carbon dioxide $\left(\mathrm{CO}_{2}\right)$, water vapour $\left(\mathrm{H}_{2} \mathrm{O}\right)$, unburned hydrocarbon (UHC), particulate matter (PM), nitrous oxide (NOX), sulphuric oxide (SOX) and excess of atmospheric oxygen and nitrogen. These emissions will definitely contribute to the GHG effects. Aware of these crises, tremendous efforts have been thoroughly planned such as Clean Sky JTI Projects by European countries, The Environmentally Responsible Aviation Project (ERA) by NASA and lots more. However, studies have shown that the development of more efficient technologies in aircraft engines reduces GHG emission up to $18 \%$ is still far below the goal of reducing $50 \% \mathrm{CO}_{2}$ emissions by 2050 (Payan et al., 2014). Due to these circumstances, aviation industries have shifted their strategy to use alternative fuels that are based from biofuels. Drop-in fuels and blended fuels in aircraft engines have significantly gained attention and interest from engineers and researchers globally. Drop-in fuels need less or no modification at all in the aircraft engine in service. It offers a future 'greener' aircraft and less dependency on crude oil.

Three successful biofuel flights of commercial aircraft are Air New Zealand's Boeing 747-400, Continental Airlines Boeing 737-800 and Japan Airline Boeing 747-300. From these examples, it is found that there are no obvious signs of Synthetic Paraffinic Kerosene (SPK) blend impacting different engine operations using biofuel blended of up to $50 \%$ with conventional fuel (Rahmes et al., 2009). Following the successful flights of many commercial aircraft running with different biofuels, this reinforces that biofuel is a viable choice to sustain the environment as well as the energy. Several test flights have already been performed on blends of conventional jet fuel and bio-jet fuel from algae, Camelina, Jatropha and other plant-based feedstocks on commercial airlines and military aircraft (Fortier et al., 2014). However, sustainability is the main concern for biofuels in order to become a source of jet fuel. This refers to the ability of the biofuel to conserve ecological balance between productivity, biodiversity and natural sources. It is also worthy of mentioning that the usage of biofuels should not be compared with food production which has high oil yield in fast-growing crops.

The present study focuses on two aspects: aircraft engine performances and exhaust emissions analysis of these alternative fuels. First, the aircraft engine performance analysis studies the effect of different blended mixing ratio percentages of biofuels on aircraft engine performance especially on thrust, fuel flow and specific fuel consumption 
(SFC) at different flight conditions. Two pure and blended biofuels (Jatropha Biofuel (BJ) and Camelina Biofuel (BC)) are evaluated at $20 \%, 40 \%, 60 \%$ and $80 \%$ of mixing ratio with kerosene. These fuels are selected following the success of the tested flight conducted on the commercial aircraft, drop-in fuel feasibility and comparable with open literature. A model three-shaft high-bypass-ratio engine, similar to RB211-524, was used throughout the analysis for validation and comparison with a RB211 variant in the work of Rahmes et al. (2009). Next, the emission analysis is presented to study the gas emission of NOX and CO with respect to these blended biofuels at different flight conditions.

Our in-house computer software was used for the computational analysis. PYTHIA was used for the engine performance analysis, whereas HEPHAESTUS was used for the emission analysis. PYTHIA utilised Newton-Raphson method convergence technique in a zero-dimensional steady-state model (Igie and Minervino, 2014) and it is integrated with our TURBOMATCH (Macmillan, 1974) code. PYTHIA is considered to be userfriendly (Mazlan et al., 2015) and has a novel interface for engine component selection that has the ability to design and calculate various gas turbine engines performances for both design and off-design points (PYTHIA interface shown in the appendix). HEPHAESTUS utilised the Zeldovich equations (for NOX) and modeled the emissions by implementing partially-stirred reactor (PSR) model in the first part of the combustor primary zone, and a series of perfectly stirred reactor (PSRS) models in later part of the combustor primary, intermediate, and dilution zones of conventional combustors. The configuration of the divided zones in the reactor is illustrated in Figure 1.

Figure 1 The configuration of divided zone in the reactor of the combustor

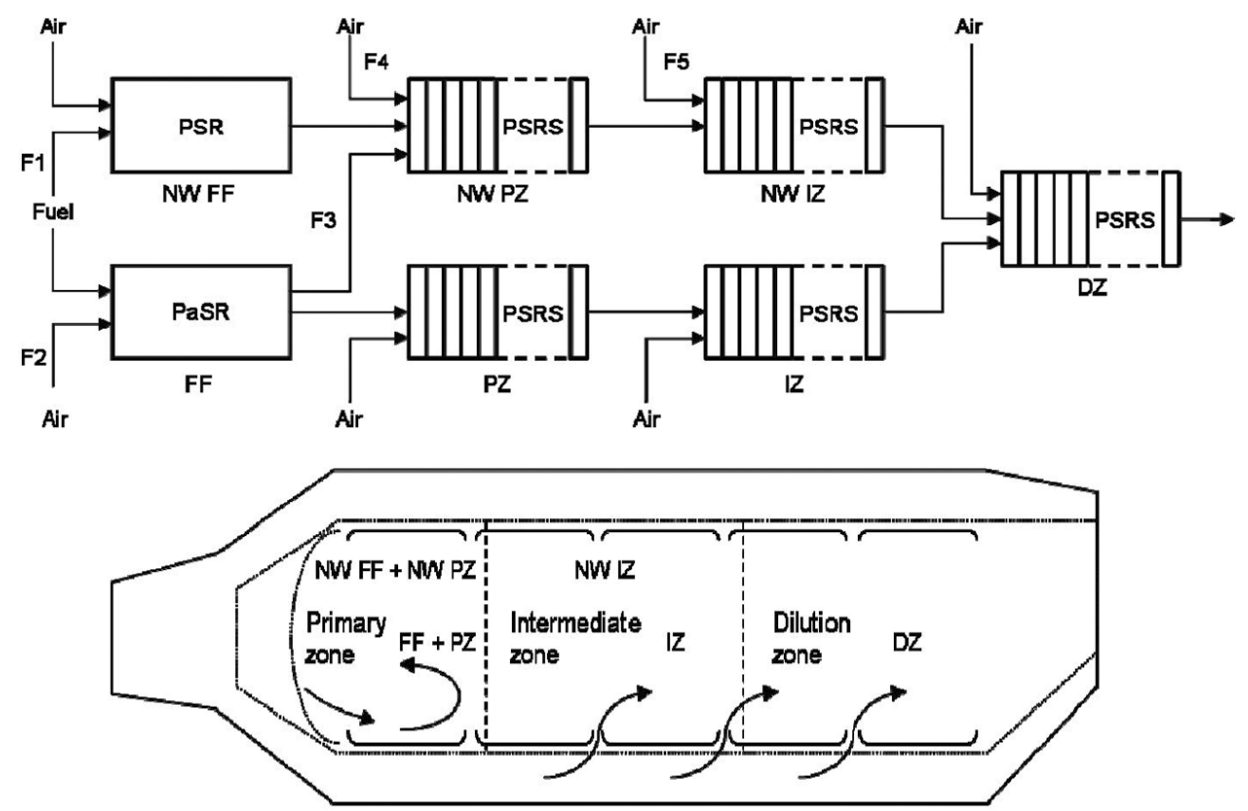

Source: Mazlan, 2012 
PYTHIA and HEPHAESTUS capabilities have been tested and validated for many years (Li et al., 2011, 2012) ranging from the industrial gas turbine and aero gas turbine. The new version of PYTHIA has the capability to accommodate off-design conditions by changing the fuel type and varying the blended mixing ratio percentage. This is essential to evaluate fit-for-purpose fuel for real engines at various operating points. As the prediction of NOX and CO emission is complex and has become an active research area, this paper brings together the performance and emission analysis and makes a systematic study of its practicability in aircraft engine which has not been addressed in Azami and Savill (2016). Therefore, this paper serves as an extension of the previous works by accommodating both performance and emission analysis in our in-house software. It also offers wider prospects and opportunities for fuels selection versatility in both performance and emission researchers in gas turbine engines.

\section{Methods}

Both performance and emission studies are analysed separately using different software. TURBOMATCH became the computing core (the processor) integrated into PYTHIA (Macmillan, 1974). TURBOMATCH and PYTHIA will execute results accordingly while keeping the design conditions at fixed value. TURBOMATCH is called for the iterations in mass (Eq. 1) and energy (Eq. 2) balance relation. Equations (1) and (2) should be satisfied between successive components, via component matching, for example, between compressor and turbine and also a compatibility equation between turbine and nozzle. For a full range of gas turbine engines to be considered, every new shaft will involve two new unknowns that must be solved iteratively and two new equations must be introduced between the original components and the new one (Macmillan, 1974). New initial guess for pressure ratio, temperature (burner) and rotational speed must be made before the iteration process. The iteration process will need several initial guess values before it converges. Further details on the TURBOMATCH process are provided and explained in Macmillan (1974). The flowchart of the PYTHIA process is illustrated in Figure 2. It begins with the user defining inputs as previously mentioned in PYTHIA. Compressor and turbine maps were needed for mass balance iteration process. NASA Chemical Equilibrium Analysis (CEA) is applied for the evaluation of thermochemical fuel properties such as the correlation of enthalpy, flame temperature, specific heat and molecular formula to the function of temperature. These correlations are stored in the TURBOMATCH library data:

$$
\frac{W_{n} \sqrt{T_{n}}}{P_{n}}=\frac{W_{n+1} \sqrt{T_{n+1}}}{P_{n+1}}
$$

$$
\text { TurbineWork }(T M)=\text { Compressor } W o r k(C W)
$$


Figure 2 PYTHIA data process flowchart (see online version for colours)
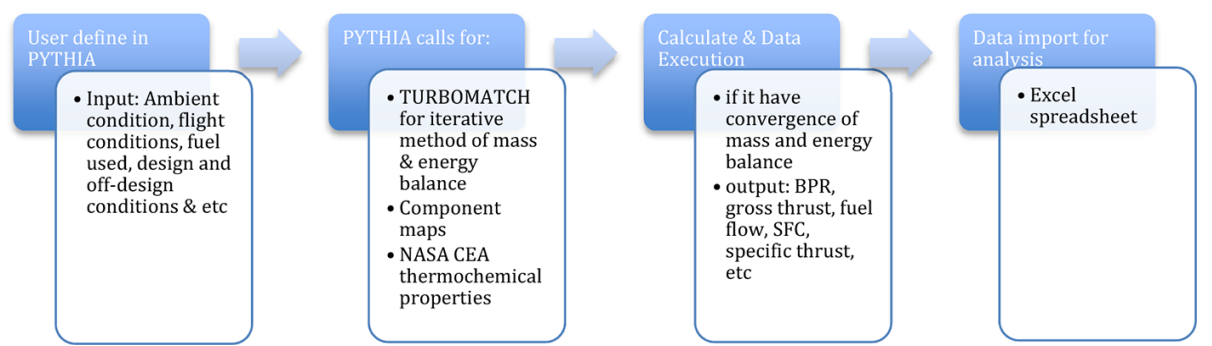

Source: Azami and Savill, 2016

Results obtained from PYTHIA in the combustor inlet conditions are used in HEPHAESTUS. The model engine configurations are specified in PYTHIA and illustrated in Figure 3. Results for the engine parameters and performance for the baseline fuel are tabulated in Table 1 and the fuel properties used in the analysis are included in the appendix. At design point, kerosene fuel was selected. Each component of the engine model is described in terms of 'bricks' which has its functionality. Initially, the ambient conditions were ascribed according to the intended flight conditions such as altitude, flight speed, mass flow, pressure recovery, pressure deviation and relative humidity in the intake 'brick'. The configuration of this engine was specified in PYTHIA using available library data and default settings. When the engine model is selected, 13 block data are arranged accordingly for: INTAKE, COMPRE1, PREMAS, COMPRE2, COMPRE3, BURNER, MIXEES, TURBIN1, TURBIN2, TURBIN3, MIXFUL, DUCTER and NOZCON as shown in Figure 3. Most bricks are defined as an individual component treating thermodynamic processes independently. However, they have to be linked to perform a complete engine simulation. In engine simulation, the properties and thermodynamic state of gasses at the entry of every Brick can be collected as a Station Vector (SV) to connect each brick. Each SV consists of following eight items (Li and Singh, 2005):

1 fuel-air ratio

2 mass flow

3 static pressure

4 total pressure

5 static temperature

6 total temperature

7 velocity

8 area. 
Figure 3 Model engine configurations in PYTHIA (see online version for colours)

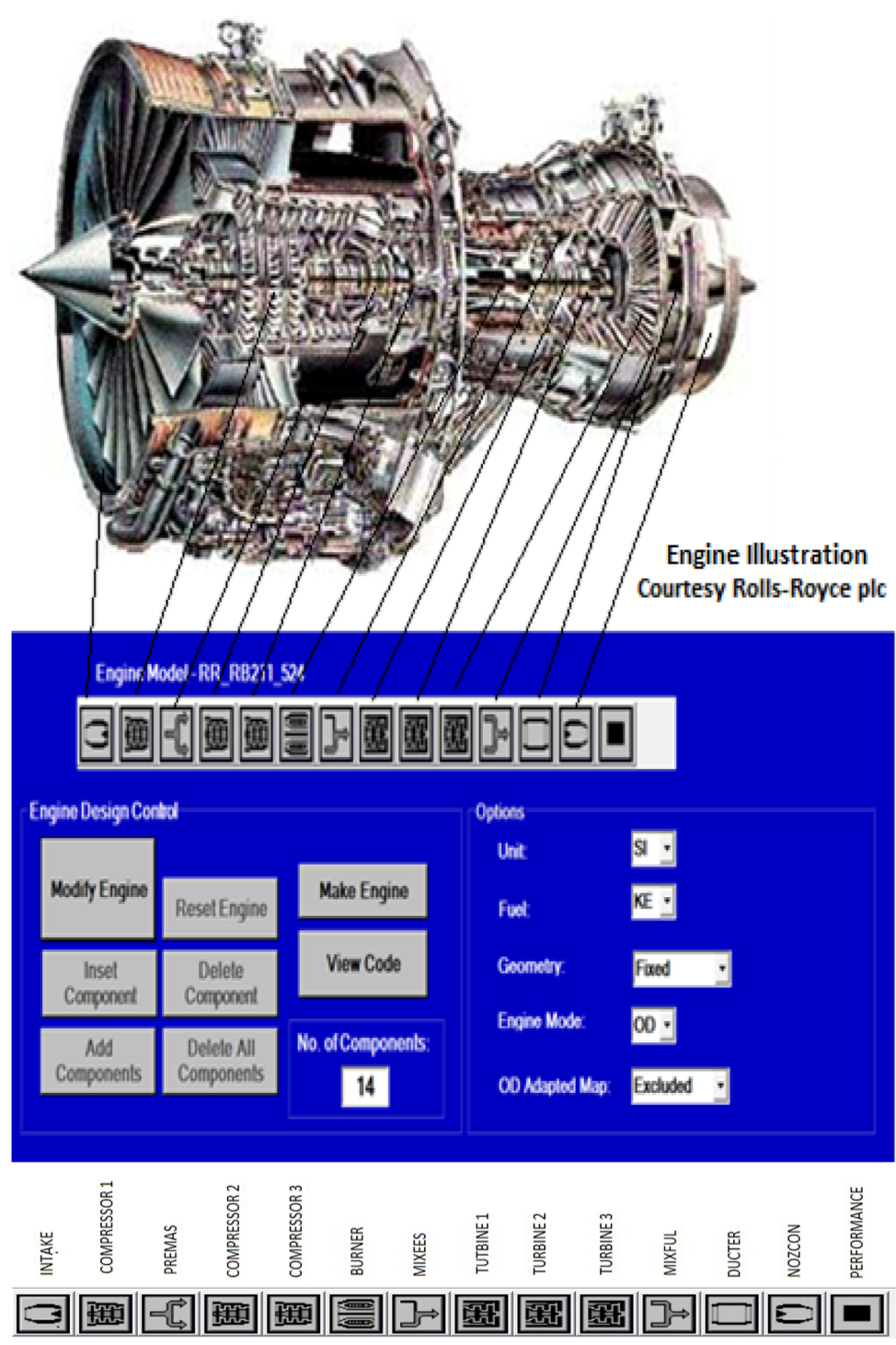

Source: Azami and Savill, 2016

Table 1 Engine parameters

\begin{tabular}{lc}
\hline Intake & \\
Altitude $(\mathrm{m})$ & 10,588 \\
Flight Mach number & 0.84 (cruise) \\
& 0.34 (climb) \\
Mass flow intake (kg/s) & 670 \\
Combustors & \\
ETA & 0.99 \\
\hline
\end{tabular}


Table 1 Engine parameters

\begin{tabular}{lc}
\hline Pressure drop $(\mathrm{atm})$ & 1.29 \\
Fuel flow $(\mathrm{kg} / \mathrm{s})$ & 2.18 \\
LHV $(\mathrm{MJ} / \mathrm{g})$ & $43.12(\mathrm{KE})$ \\
FAR & $0.02(\mathrm{BC}) 44.3(\mathrm{BJ})$ \\
Engine performances & \\
BPR & 4.3 \\
Gross thrust $(\mathrm{kN})$ & 293.38 \\
Fuel flow $(\mathrm{kg} / \mathrm{s})$ & 2.18 \\
SFC $(\mathrm{kg} / \mathrm{Ns})$ & 21.07 \\
\hline
\end{tabular}

Figure 4 shows the schematic diagram of a brick inputs and outputs. For off-design conditions, three design parameters were adjusted accordingly in the burner 'brick', which are the fuel combination, second fuel type and fuel-mixing rate. Fuel combination parameter represents the condition of how the fuel is mixed. Apparently, there are three options for selection; keeping the original fuel, replacing the original fuel and mixing the fuel. The second fuel type is defined as the type of second fuel used. Fuel-mixing rate signifies the blending mixing ratio percentages from 0 to 1 , where 1 is represents the pure second-type fuel.

Figure 4 Schematic diagram of brick data

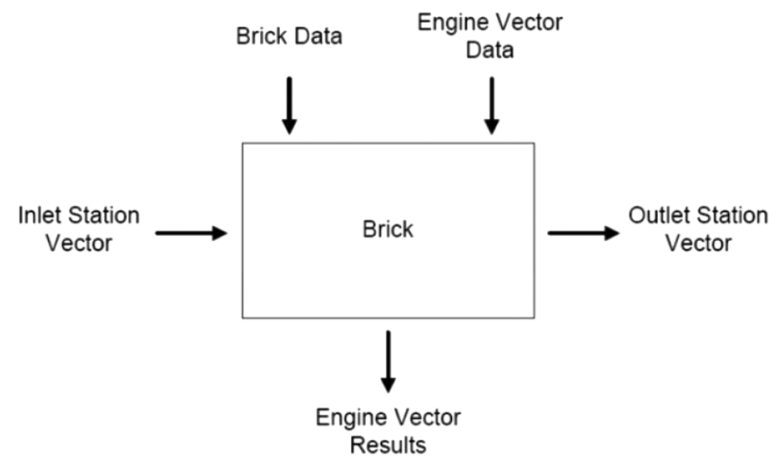

Source: Li and Singh, 2005

As previously mentioned, HEPHAESTUS requires several input data obtained from PYTHIA in combustor 'brick' data. Other parameters such as the combustor geometries, fuel total temperature, ambient conditions (altitude, temperature and relative humidity), air total pressure and temperature at the combustor inlet, fuel and total air mass flow rate are needed prior to the analysis. Combustor geometries are kept constant as per value used in Celis (2010) and Mazlan (2012). However, only the predictions of kerosene and BJ blended fuels for NOX and CO are considered in the emission analysis. Although there are quite a number of emission methods available to predict emission in the literature, HEPHAESTUS has shown its capability and versatility to predict emissions generated from biofuels with ease. Few assumptions need to be addressed prior to HEPHAESTUS analysis such as fuel evaporation, combustion unsteadiness and flow 
circulation in the combustor are not included. These assumptions are deliberately elaborated in Celis (2010) and Mazlan (2012).

\section{Results and discussion}

\subsection{Engine performance validation}

Prior to the analysis, the engine model developed in PYTHIA was validated by comparing with experimental work previously carried out by Rahmes et al. (2009), who conducted an off-wing engine ground test of an RB211-524 fuelled with 50\% Jatropha/50\% Jet-A on a Boeing 747-400 of the Air New Zealand airline. It appears that the fuel flow and percentage HV differences were comparable with the engine model, exhibiting only a slight difference as shown in Figure 5.

Figure 5 Performance validation of blended kerosene/BJ (see online version for colours)

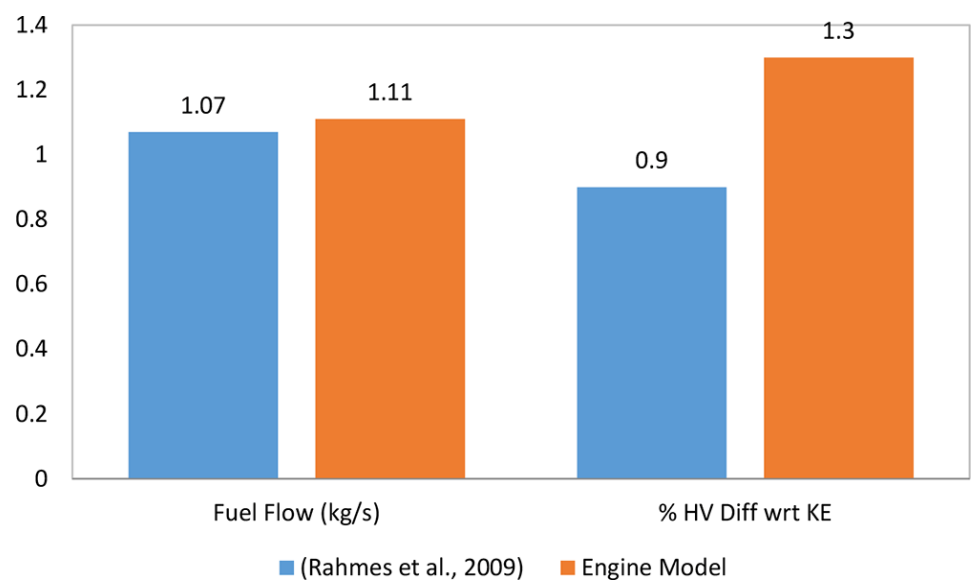

\subsection{Performance analysis}

\subsubsection{Take-off}

Initially, the propulsive performance at take-off condition is evaluated and analysed for different percentage blended mixing ratio. The ambient and initial flight conditions are adjusted accordingly in the first block diagram. Figure 6 demonstrates the

1 gross thrust

2 fuel flow

$3 \mathrm{SFC}$ 
Figure 6 Variation of (a) gross thrust, (b) fuel flow and (c) SFC and its percentage difference with respect to pure kerosene at different mixing ratio (see online version for colours)

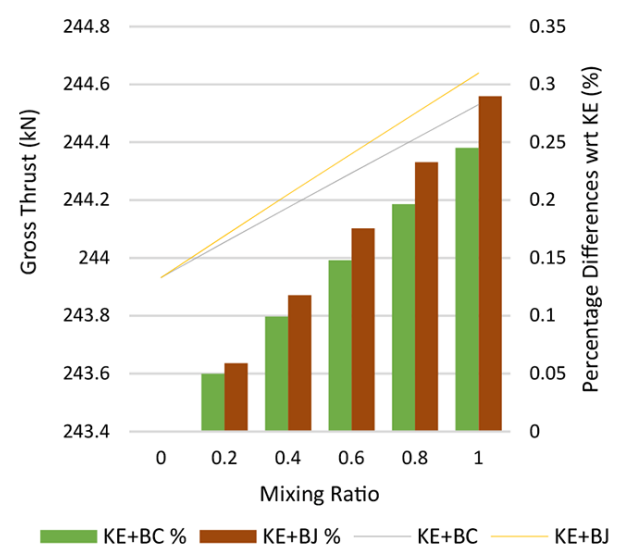

(a)

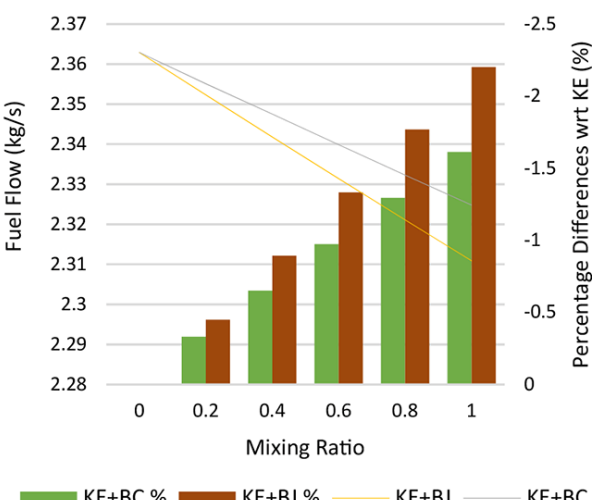

(b)

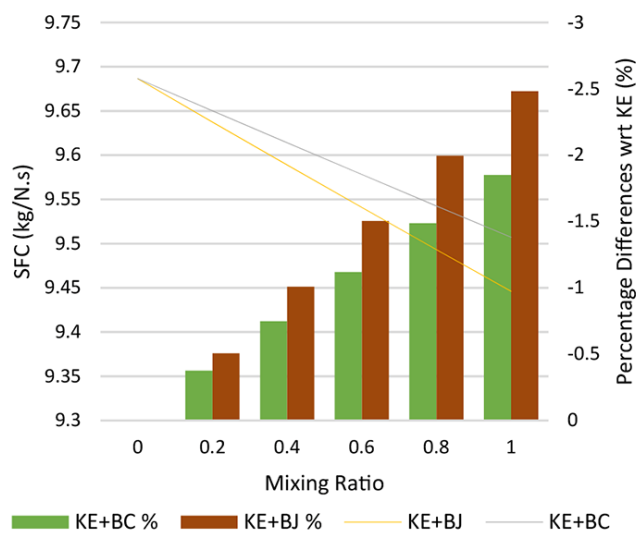

(c)

Variations and percentage differences as compared with kerosene at different mixing ratios. There was an increase in gross thrust for both fuel combinations as the mixing ratio moves towards pure biofuel (high mixing ratio). BJ pure biofuel showed $0.29 \%$ increase in gross thrust. The difference started to become more severe at higher mixing ratios. Fuel flow results revealed a reduction for both fuels as the mixing ratio was increased. The reduction was up to $2.2 \%$ and $1.6 \%$ of fuel flow for pure $\mathrm{BJ}$ and $\mathrm{BC}$, respectively. Both fuels exhibited a reduction in SFC as the mixing ratio was increased. SFC was reduced up to $2.48 \%$ for BJ pure fuel, while for BC, it was reduced by $1.85 \%$. These results thus suggest that better performance can be achieved using pure alternative fuels due to higher lower heating value (LHV). Detailed explanations are discussed at the end of this section. 


\subsubsection{Cruise}

Cruise conditions as mentioned previously in Table 1 are used. Figure 7 illustrates the

1 gross thrust

2 fuel flow

3 SFC

Figure 7 Variation of (a) gross thrust, (b) fuel flow and (c) SFC and its percentage difference with respect to pure kerosene at different mixing ratios (see online version for colours)

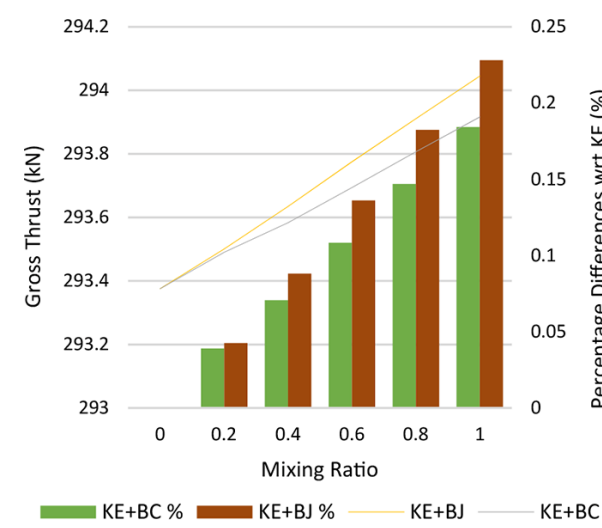

(a)

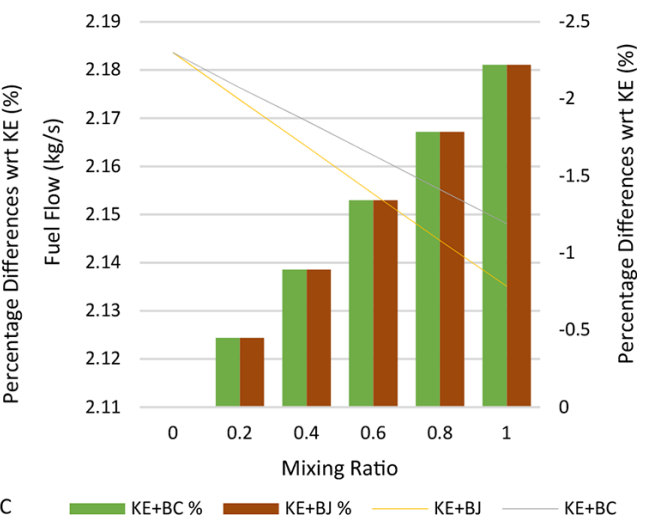

(b)

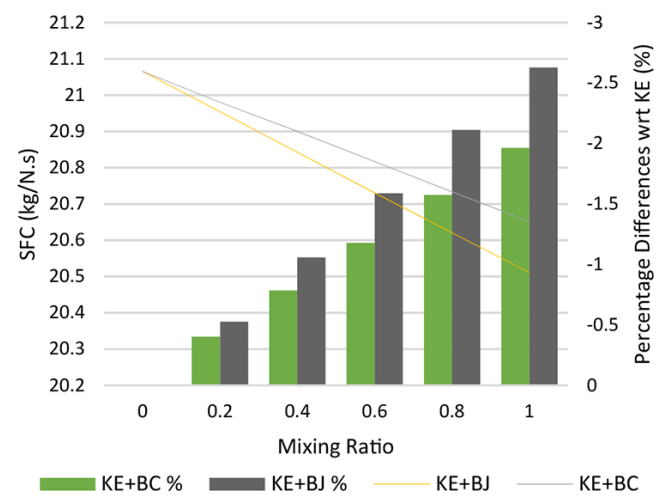

(c)

Variations and percentage differences as compared to kerosene. Similarly, there was an increase in gross thrust for both fuel combinations as the mixing ratio increases. It should be noted also that there is a slight reduction of gross thrust percentage differences in cruise condition compared to the take-off condition. Likewise, the fuel flow and SFC demonstrated a reduction for both fuel as the mixing ratio increased. There were not many differences between cruise and take-off conditions, for the fuel flow. However, $\mathrm{SFC}$ was reduced more in the cruise condition as compared to the take-off condition. 
Results indicate a higher percentage of blended fuel demonstrate better propulsive performances. Comparisons of these pure alternative fuels can be summarised in Figure 8 for different flight conditions. Clearly, BJ performs much better than $\mathrm{BC}$ for gross thrust, more reduction in fuel flow and SFC for both different flight conditions. Furthermore, as the fuel flow and SFC give more improvement in cruise, however, there is a slight reduction in gross thrust at cruise condition as compared in take-off for both fuels.

Figure 8 Performance comparison of pure alternative fuel at different flight conditions (see online version for colours)

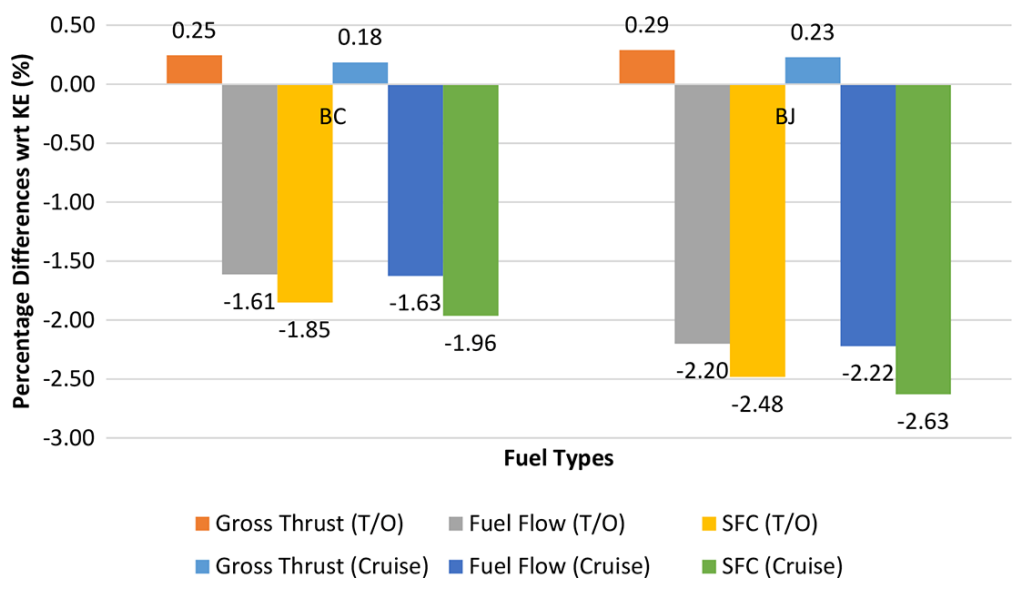

As alternative fuels are introduced into the combustor, few assumptions should be addressed. Combustion efficiency is assumed to remain fixed for all fuels which turned out to be varied in terms of fuel atomisation and spray characteristics due to the differences in thermochemical properties. The properties of alternative fuels used are taken directly from the published literature without taking consideration of ASTM approval and the fuel process methodology. Focusing only on the combustor with different of blended fuels, several results can be drawn due to the effect of the changed thermochemical properties. It is observed that the total pressure, the mass flow and the pressure drop increased slightly at higher percentage blended mixing ratio. As the total pressure and mass flow rise, the exit velocity is increased and this has resulted in an increase in gross thrust. However, the pressure drop in the combustor is increased as well. Furthermore, the fuel-to-air ratio (FAR) is reduced, indicating that more air is introduced to complete the burning. These explained more fuel flow reduction at higher mixing ratio blend. Although large LHV fuel gives a better propulsive performance, it is more likely to require more air for combustion. Another crucial parameter is the turbine inlet temperature (TIT) as it determines the propulsive performances but there are limitations to set the value due to the turbine materials integrity as well as observing NOX exhaust emission due to high temperature. TIT was set to $1,580 \mathrm{~K}$ for all cases. It is observed that high LHV fuel able to sustain the temperature longer which essentially important to expand and convert high energy to useful work and kinetic energy. 


\subsection{Emission analysis}

This section studies the emission of these blended biofuels based on the performance parameters obtained in the previous analysis using PYTHIA. In HEPHAESTUS, kerosene fuel is selected as the baseline fuel. An LTO cycle includes three phases of an aircraft mission: cruise, climb and take-off. In the later section, the emission is analysed at different combustor inlet conditions. It is, however, only $50 \%$ blended $\mathrm{KE}+\mathrm{BJ}$ (known as BJ50) and pure BJ fuel will be discussed due to limited capability in HEPHAESTUS. Prior to the analysis, it was observed to follow the trends provided in ICAO databank as shown in Figure 9. Among the three flight conditions, cruise phase has the largest differences as the ICOA databank covers only up to $3,000 \mathrm{ft}$ altitude (Chandrasekaran and Guha, 2012). A list of emissions emitted and its differences with respect to kerosene fuel is tabulated in Table 2 for comparison. It is observed that blended and pure biofuel contributes to the reduction in EINOX at every flight condition for about 4-12\% with respect to kerosene fuel. Pure Jatropha biofuel demonstrates the most NOx reduction. Nevertheless, EICO values for these blended biofuels predicted by HEPHAESTUS depicted a slight increase for about $2 \%$ (except for BJ fuel). Yet, pure Jatropha biofuel has a much lower increase in EICO as compared to BJ50.

Figure 9 Emission comparison of baseline kerosene fuel at different flight conditions with ICAO databank (see online version for colours)

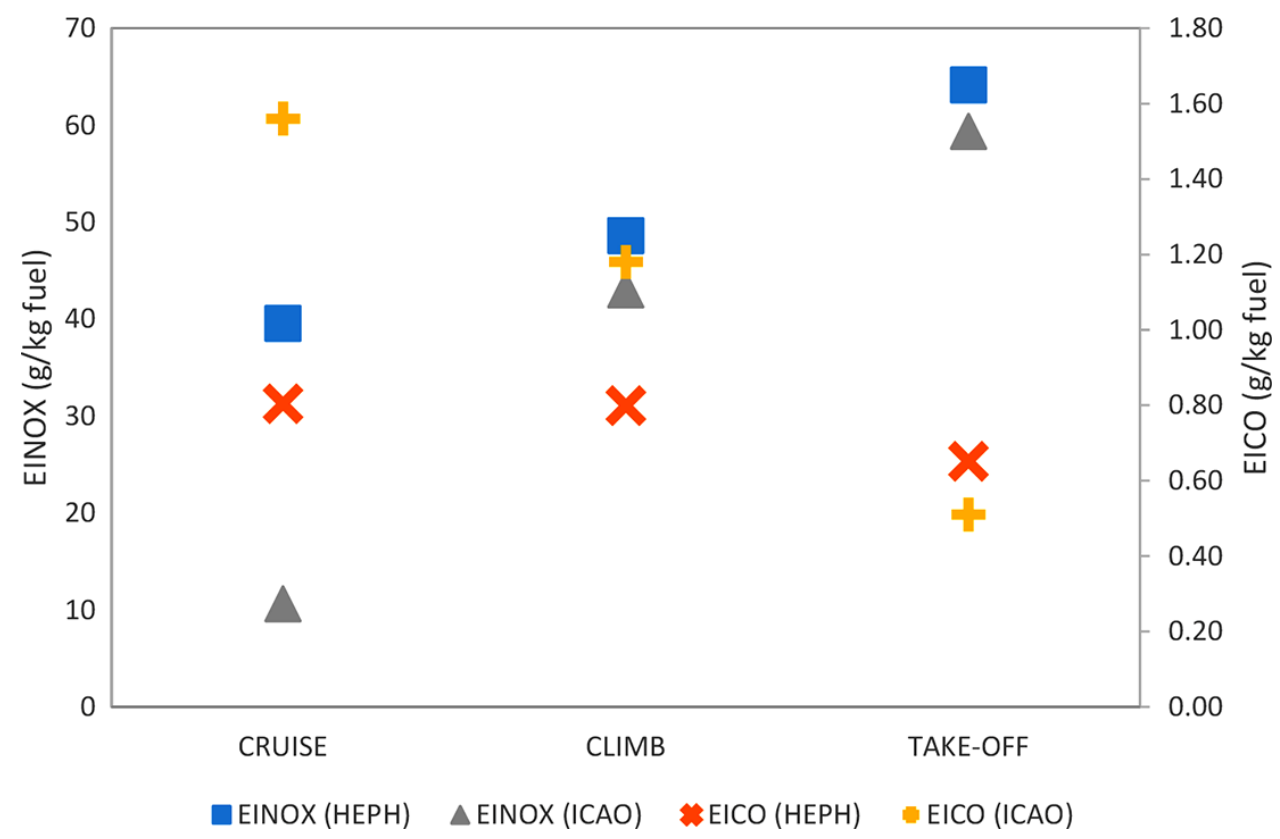


Table 2 Emission comparison of alternative blended biofuels at different flight conditions

\begin{tabular}{|c|c|c|c|c|c|c|c|c|c|}
\hline & $T A(K)$ & $\begin{array}{c}P A \\
(\mathrm{~atm})\end{array}$ & $\begin{array}{c}W A \\
(\mathrm{~kg} / \mathrm{s})\end{array}$ & $W F(\mathrm{~kg} / \mathrm{s})$ & $T F(K)$ & $\begin{array}{c}\text { EINOX } \\
\text { (g/kg fuel) }\end{array}$ & $\begin{array}{c}\text { EICO } \\
(\mathrm{g} / \mathrm{kg} \text { fuel })\end{array}$ & $\begin{array}{c}\Delta \% E I N O X \\
\text { wrt } K E\end{array}$ & $\begin{array}{c}\Delta \% E I C O \\
\text { wrt } K E\end{array}$ \\
\hline \multicolumn{10}{|c|}{ Cruise } \\
\hline $\mathrm{KE}$ & 840.39 & 19.56 & 72.26 & 1.54 & 413.74 & 39.56 & 0.80 & & \\
\hline BJ50 & 840.88 & 19.58 & 72.35 & 1.53 & 413.82 & 37.22 & 0.81 & -5.91 & 0.75 \\
\hline BJ & 841.37 & 19.60 & 72.44 & 1.51 & 413.90 & 35.70 & 0.81 & -9.77 & 0.55 \\
\hline \multicolumn{10}{|c|}{ Climb } \\
\hline $\mathrm{KE}$ & 847.24 & 21.17 & 72.02 & 1.53 & 413.93 & 48.60 & 0.80 & & \\
\hline BJ50 & 845.98 & 20.95 & 71.33 & 1.50 & 414.00 & 44.66 & 0.81 & -8.11 & 1.97 \\
\hline BJ & 846.51 & 20.98 & 71.43 & 1.48 & 414.08 & 42.86 & 0.81 & -11.82 & 1.76 \\
\hline \multicolumn{10}{|c|}{ Take-off } \\
\hline $\mathrm{KE}$ & 852.08 & 30.69 & 113.62 & 2.43 & 414.28 & 64.15 & 0.65 & & \\
\hline BJ50 & 853.59 & 30.95 & 114.6 & 2.41 & 414.35 & 61.30 & 0.65 & -4.44 & 0.18 \\
\hline BJ & 854.19 & 31.01 & 114.89 & 2.39 & 414.43 & 58.94 & 0.65 & -8.13 & -0.03 \\
\hline
\end{tabular}

\subsubsection{Variation of combustor inlet conditions}

Variations of different inlet conditions such as combustor inlet pressure, temperature, mass flow rate and fuel flow rate are presented in this section. The left side of Figure 10a-c illustrates the EINOX and EICO variations under the influence of combustor inlet pressure. Results display an increase in EINOX as the combustor inlet pressure increases at every flight condition, but pure Jatropha biofuel has much lower EINOX emission. Similarly, EICO variations increased as inlet pressure increases except for take-off flight phase condition. At this condition, EICO has the highest value at about $30 \mathrm{~atm}$ before it starts to decline. As expected, BJ50 fuel has much higher EICO than other fuels. Moreover, the right side of Figure $10 \mathrm{~d}-\mathrm{f}$ depicted the influence of combustor inlet temperature to EINOX and EICO variations. Apparently, the opposite effects occurred in EINOX and EICO variants; EINOX increases and EICO decreases as the combustor inlet temperature increases. EINOX emission increases as the combustor inlet mass flow increase for every flight condition as illustrated in Figure 11a-c. Conversely, the effect fuel flow reduces the EINOX as shown in Figure 11d-f. Meanwhile, EICO has an optimum inlet mass flow rate and fuel flow rate for different flight phases before it starts to decline. For cruise and climbing phases, the highest EICO occurred at $1.5 \mathrm{~kg} / \mathrm{s}$ of fuel flow, while during take-off, it is about $2.5 \mathrm{~kg} / \mathrm{s}$. From the preceding results in Figures 10 and 11, it can be summarised as follows:

1 EINOX can be reduced at lower combustor inlet pressure, inlet temperature and inlet mass flow but higher fuel flow rate.

2 EICO can be minimised at lower combustor inlet pressure (only at cruise and climbing phases) and higher inlet temperature, However, combustor inlet mass flow and the fuel flow rate have its optimum operating initial conditions and are dependent on the flight conditions. 
$3 \mathrm{BJ} 50$ and BJ pure fuel can reduce EINOX for every flight condition. Nevertheless, the trends in EICO emissions depend on the flight conditions as well as variations of combustor inlet conditions.

Figure 10 Emission comparison of combustor inlet pressure variations, (a)-(c) and inlet temperature variations, (d)-(f), at different flight conditions (see online version for colours)

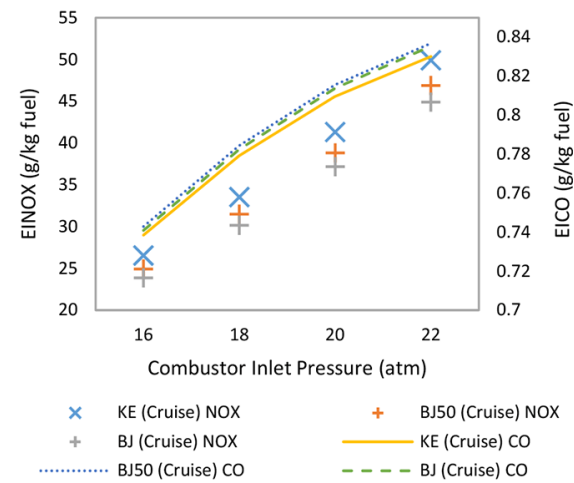

(a)

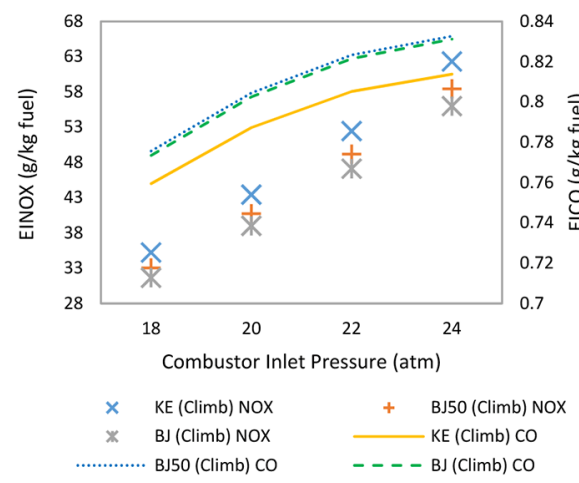

(b)

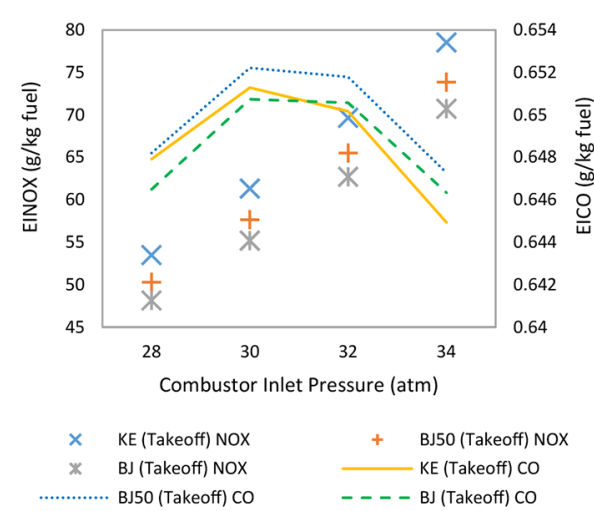

(c)

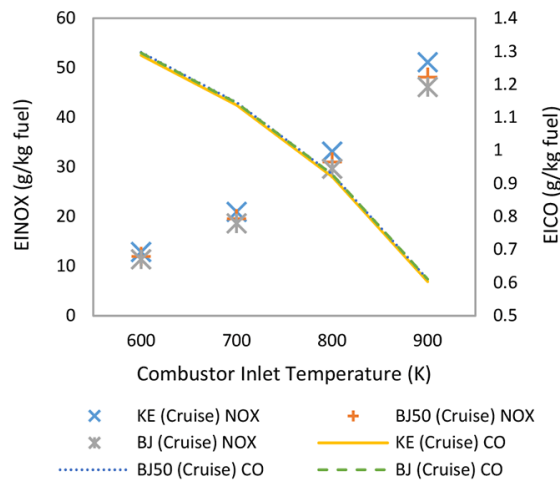

(d)

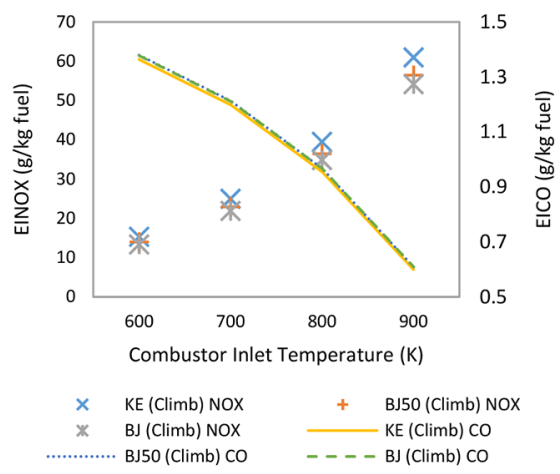

(e)

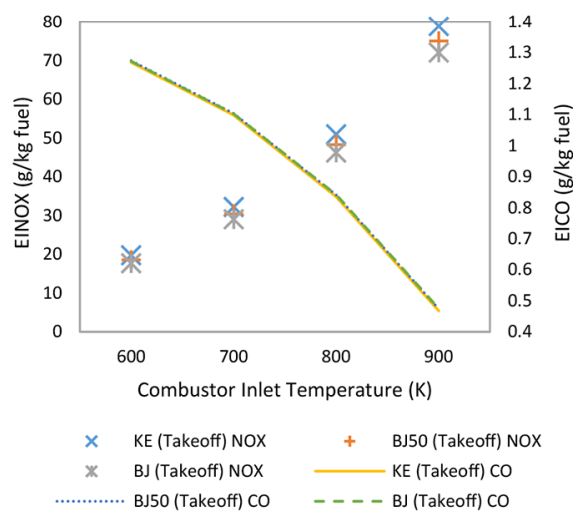

(f) 
Figure 11 Emission comparison of combustor inlet mass flow variations (a)-(c), and inlet fuel flow variations, (d)-(f), at different flight conditions (see online version for colours)

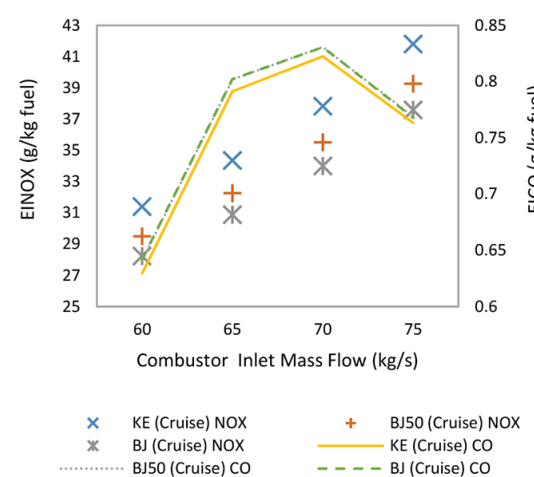

(a)

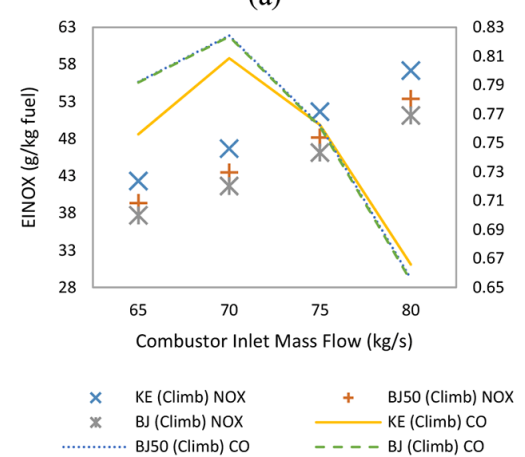

(b)

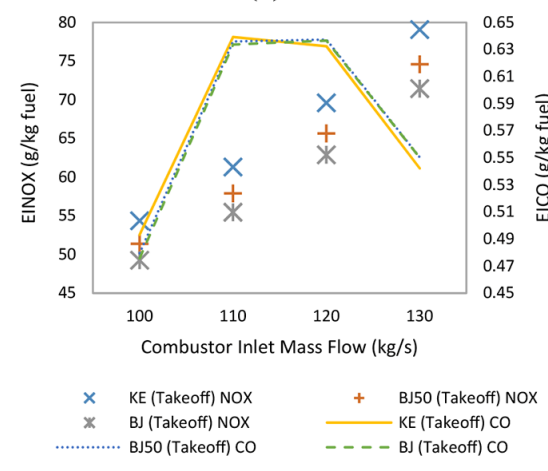

(c)

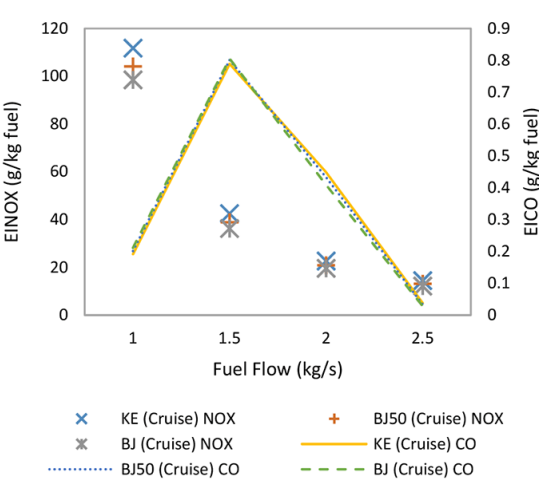

(d)

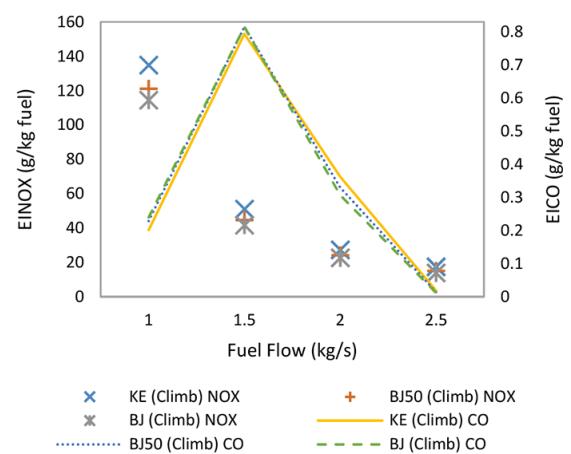

(e)

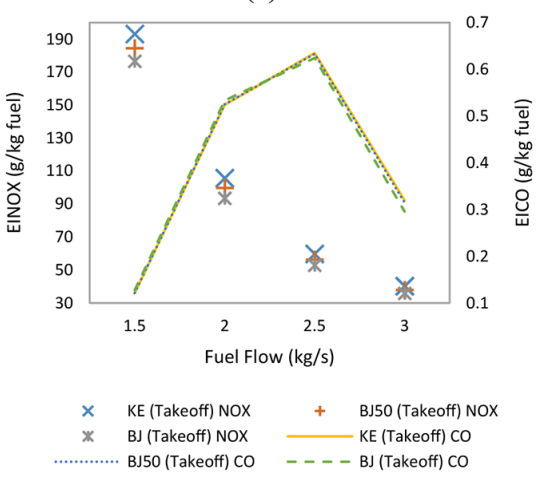

(f)

\section{Conclusion}

Many important findings are brought together in this paper in terms of aircraft engine performance and emissions for alternative fuels using, respectively, in-house software codes: PYTHIA and HEPHAESTUS. It is observed that the LHV of the fuel has a significant influence on the engine performance metrics such as thrust, fuel flow and SFC 
at every flight condition and at different blended mixing ratio percentages. Results indicate a higher percentage of blended fuel demonstrated better propulsive performances. Clearly, Jatropha Biofuel performs much better than Camelina Biofuel for gross thrust, more reduction in fuel flow and SFC.

Emission analysis has been included in this paper and at the same time, its prediction of EINOX and EICO compares well with that of the ICAO databank. We have also shown that the combustor inlet conditions take an important role to determine EINOX and EICO emissions. For such variations, alternative fuels can reduce EINOX as compared to kerosene fuel for every flight condition. However, the same is not necessarily true for EICO emissions which depend on combustor inlet conditions and flight phases.

\section{Acknowledgement}

The lead author would like to acknowledge and to thank International Islamic University Malaysia, Malaysia for the sponsoring his $\mathrm{Ph}$ research work.

\section{References}

Ashraful, A.M., Masjuki, H.H., Kalam, M.A., Fattah, I.M.R., Imtenan, S., Shahir, S.A. and Mobarak, H.M. (2014) 'Production and comparison of fuel properties, engine performance, and emission characteristics of biodiesel from various non-edible vegetable oils : a review', Energy Conversion and Management, Vol. 80, pp.202-228, doi:10.1016/ j.enconman.2014.01.037.

Atabani, A.E., Silitonga, A.S., Badruddin, I.A., Mahlia, T.M.I., Masjuki, H.H. and Mekhilef, S. (2012) 'A comprehensive review on biodiesel as an alternative energy resource and its characteristics', Renewable and Sustainable Energy Reviews, Vol. 16, No. 4, pp.2070-2093, doi:10.1016/j.rser.2012.01.003.

Azami, M.H. and Savill, M. (2016) 'Comparative study of alternative biofuels on aircraft engine performance', Proceedings of the Institution of Mechanical Engineers, Part G: Journal of Aerospace Engineering, pp.1-13, doi:10.1177/0954410016654506.

Brennan, L. and Owende, P. (2010) 'Biofuels from microalgae - a review of technologies for production, processing, and extractions of biofuels and co-products', Renewable and Sustainable Energy Reviews, Vol. 14, No. 2, pp.557-577, doi:10.1016/j.rser.2009.10.009.

Celis, C. (2010) Evaluation and Optimisation of Environmentally Friendly Aircraft Propulsion System, PhD Thesis, Cranfield University. doi: 10.1017/CBO9781107415324.004.

Chandrasekaran, N. and Guha, A. (2012) 'Study of prediction methods for NOx emission from turbofan engines', Journal of Propulsion and Power, Vol. 28, No. 1, pp.170-180, doi:10.2514/1.B34245.

Fortier, M-O.P., Roberts, G.W., Stagg-Williams, S.M. and Sturm, B.S.M. (2014) 'Life cycle assessment of bio-jet fuel from hydrothermal liquefaction of microalgae', Applied Energy, Vol. 122, July, pp.73-82, doi:10.1016/j.apenergy.2014.01.077.

Igie, U. and Minervino, O. (2014) 'Impact of inlet filter pressure loss on single and two-spool gas turbine engines for different control modes', Journal of Engineering for Gas Turbines and Power, Vol. 136, No. 9, p.091201, doi:10.1115/1.4027216.

Li, Y.G. and Singh, R. (2005) An advanced gas turbine gas path diagnostic system-PYTHIA, in XVII International Symposium on Air Breathing Engines, Munich, Germany, Paper No. ISABE-2005-1284. 
Li, Y.G., Ghafir, M.F.A., Wang, L., Singh, R., Huang, K. and Feng, X. (2011) 'Nonlinear multiple points gas turbine off-design performance adaptation using a genetic algorithm', Journal of Engineering for Gas Turbines and Power, Vol. 133, July, pp.1-9, doi:10.1115/1.4002620.

Li, Y.G., Abdul Ghafir, M.F., Wang, L., Singh, R., Huang, K., Feng, X. and Zhang, W. (2012) 'Improved multiple point nonlinear genetic algorithm based performance adaptation using least square method', Journal of Engineering for Gas Turbines and Power, Vol. 134, No. 3, p. 1, doi:10.1115/1.4004395.

Macmillan, W.L. (1974). Development of a Modular-Type Computer Program for the Calculation of Gas Turbine Off-Design Performance, PhD Thesis, Cranfield Institute of Technology.

Maity, J. P., Bundschuh, J., Chen, C-Y. and Bhattacharya, P. (2014) 'Microalgae for third generation biofuel production, mitigation of greenhouse gas emissions and wastewater treatment: Present and future perspectives - A mini review', Energy. Elsevier Ltd, Vol. 78, pp.104-113, doi: 10.1016/j.energy.2014.04.003.

Mazlan, N. M. (2012) Assessing/Optimising Bio-Fuel Combustion Technologies for Reducing Civil Aircraft Emissions, PhD Thesis, Cranfield University.

Mazlan, N.M., Savill, M. and Kipouros, T. (2015) 'Effects of biofuels properties on aircraft engine performance', Aircraft Engineering and Aerospace Technology, Vol. 87, pp.437-442, doi:10.1108/AEAT-09-2013-0166.

Payan, A.P., Kirby, M., Justin, C.Y. and Mavris, D.N. (2014) 'Meeting emissions reduction targets: a probabilistic lifecycle assessment of the production of alternative jet fuels', in AIAA/3AF Aircraft Noise and Emissions Reduction Symposium, American Institute of Aeronautics and Astronautics, Atlanta, GA, pp.1-17.

Rahmes, T.F., Kinder, J.D., Henry, T.M., Crenfedlt, G., LeDuc, G.F., Zombanakis, G.P., Abe, Y., Lambert, D.M., Lewis, C., Juenger, J.A., Andac, M.G., Reilly, K.R., Holmgren, J.R., McCall, M.J. and Bozzano, A.G. (2009) 'Sustainable bio-derived synthetic paraffinic kerosene (bio-SPK) jet fuel flights and engine tests program results', in 9th AIAA Aviation Technology, Integration, and Operations Conference (ATIO), American Institute of Aeronautics and Astronautics, Hilton Head, SC, pp.1-19, doi:10.2514/6.2009-7002.

Tüccar, G. and Aydın, K. (2013) 'Evaluation of methyl ester of microalgae oil as fuel in a diesel engine', Fuel, Vol. 112, pp.203-207, doi:10.1016/j.fuel.2013.05.016.

\section{Nomenclature}

\begin{tabular}{lc}
\hline BC & Camelina biofuel \\
BJ & Jatropha biofuel \\
BPR & bypass ratio \\
CFPP & cold filter plugging point \\
ETA & efficiency \\
FAR & fuel-to-air ratio \\
KE & kerosene \\
LHV & lower heating value \\
P & pressure \\
$P_{n}$ & pressure at n-stage \\
PR & pressure ratio \\
SFC & specific fuel consumption \\
T & temperature \\
TIT & turbine inlet temperature
\end{tabular}


$T_{n}$

$v_{a}$

WA

$W_{n}$ temperature at n-stage

flight approaching speed

$$
\text { mass flow }
$$

mass flow at n-stage

surge margin parameter

\section{Appendix}

\begin{tabular}{lcc}
\hline & Jatropha & Camelina \\
\hline Density $\left(\mathbf{k g} / \mathbf{m}^{\mathbf{3}}\right)$ & $864-880$ & - \\
Cetane number & $46-55$ & 50.4 \\
Viscosity $\left(\mathbf{m m}^{2} / \mathbf{s}\right.$ at $\left.\mathbf{4 0}{ }^{\circ} \mathbf{C}\right)$ & $3.7-5.8$ & 3.80 \\
Pour point $\left({ }^{\circ} \mathbf{C}\right)$ & 5 & -7 \\
Flash point $\left({ }^{\circ} \mathbf{C}\right)$ & $163-238$ & 136 \\
Heating value $(\mathbf{M J} / \mathbf{k g})$ & 44.4 & 44 \\
CFPP $\left({ }^{\circ} \mathbf{C}\right)$ & -1.2 & -3 \\
Acid value $(\mathbf{m g} / \mathbf{K O H})$ & 0.34 & \\
Cloud point $\left({ }^{\circ} \mathbf{C}\right)$ & 5 & 3 \\
Iodine value $\left(\mathbf{I}_{\mathbf{2}} / \mathbf{1 0 0} \mathbf{g}\right)$ & 109.5 & 152.8 \\
Sulphur content $(\mathbf{p p m})$ & 12.9 & - \\
Specific gravity $(\mathbf{g} / \mathbf{m l})$ & 0.876 & 0.882 \\
Molecular formula & $C_{12} H_{26}$ & $C_{12} H_{25.4}$ \\
\hline
\end{tabular}

PYTHIA user interface (see online version for colours)

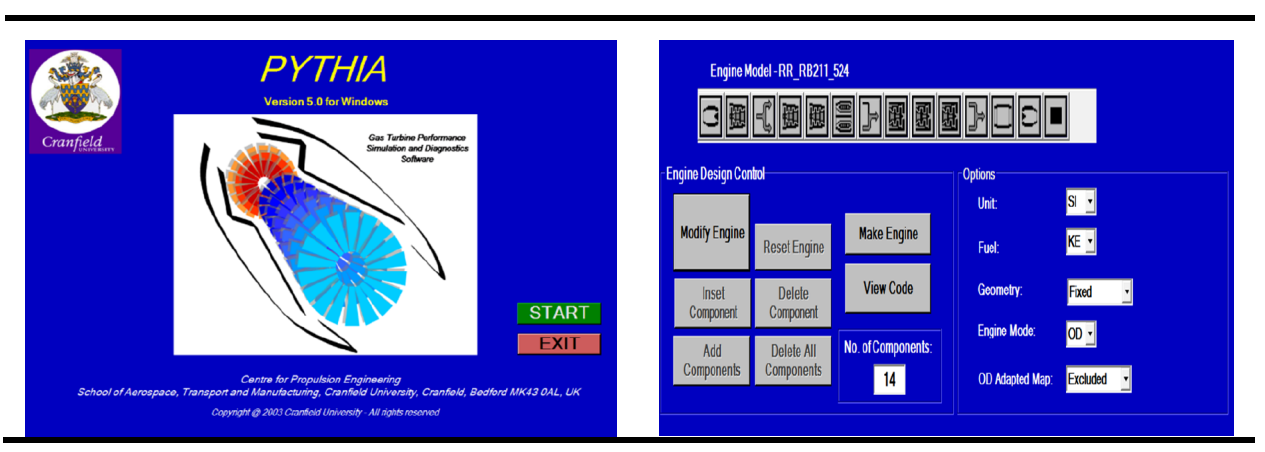


PYTHIA user interface (see online version for colours) (continued)

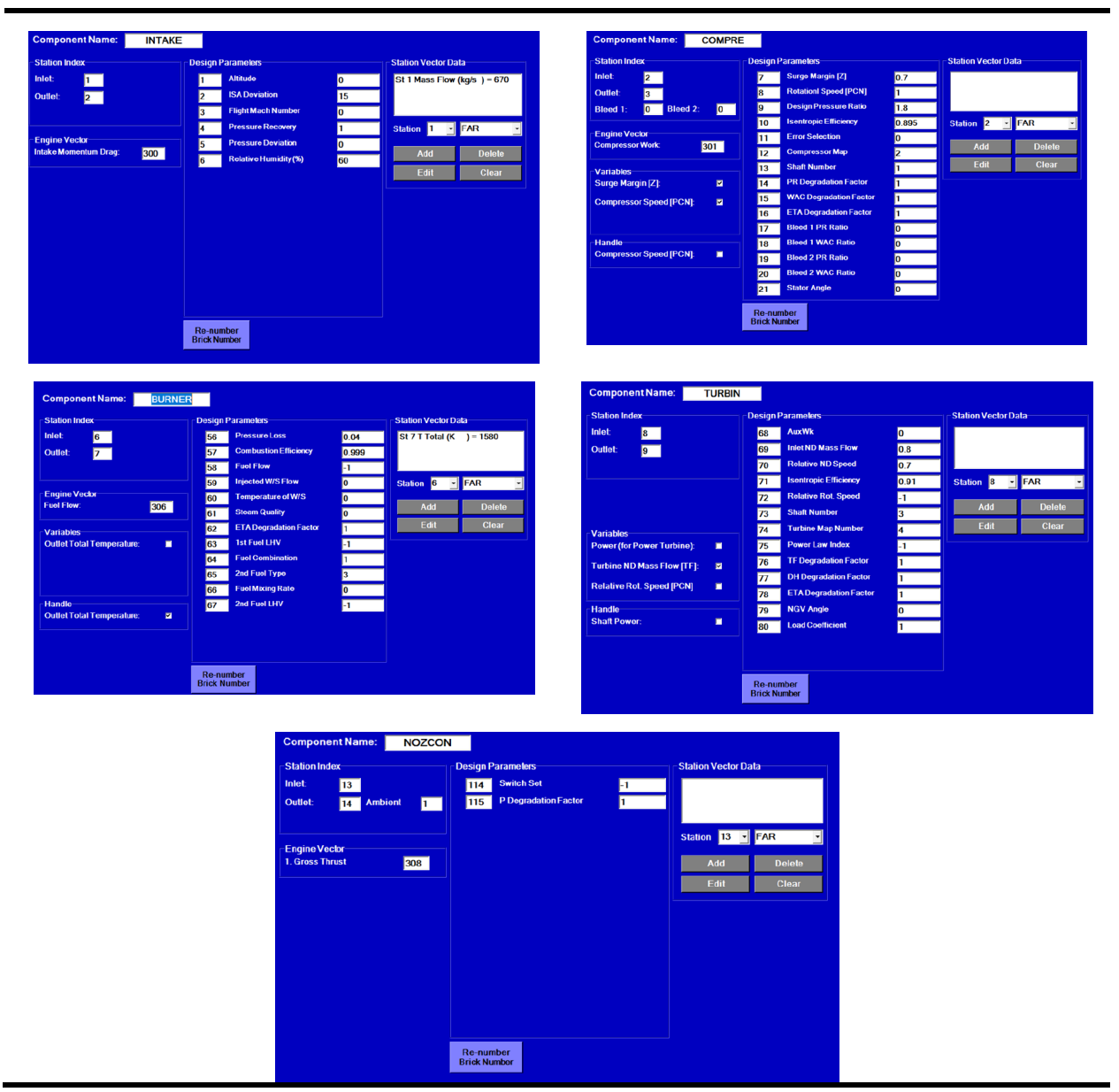

Compressor map used (see online version for colours)

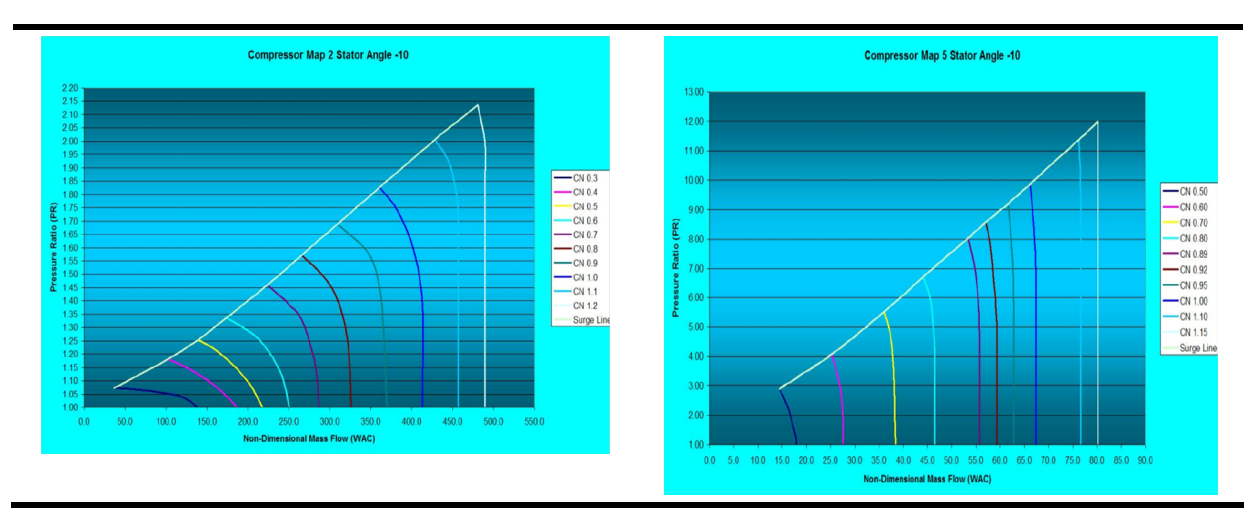


Compressor map used (see online version for colours) (continued)

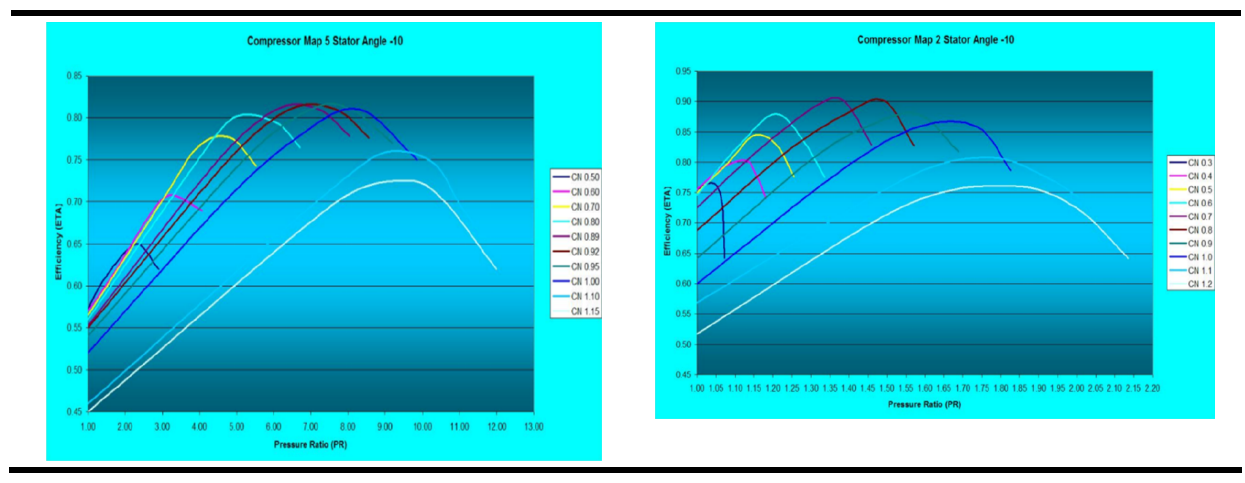

Turbine map used (see online version for colours)
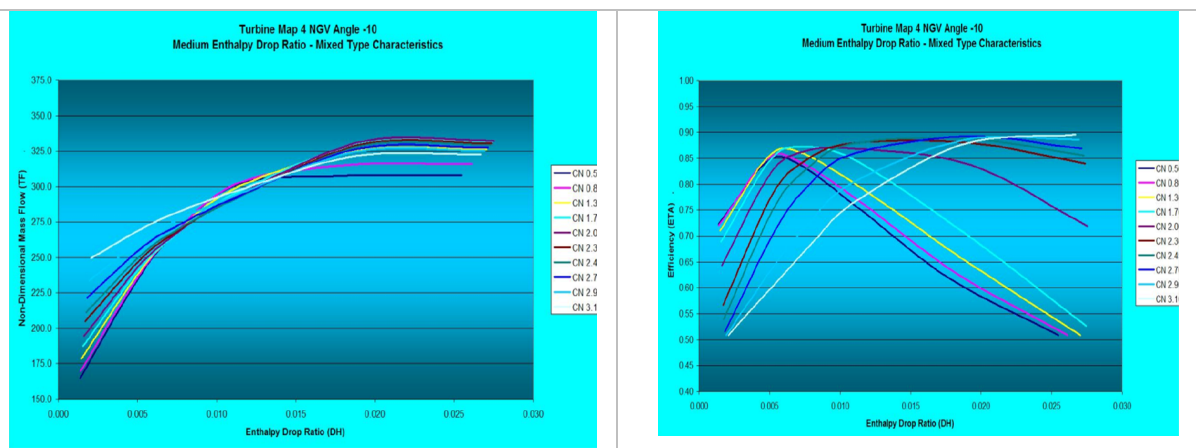